Abanico Veterinario. Enero-Diciembre 2020; 10:1-8. http://dx.doi.org/10.21929/abavet2020.25

Caso Clínico. Recibido: 01/05/2020. Aceptado: 19/08/2020. Publicado: 10/09/2020. Clave: 2020-55.

\title{
Reporte de rabia en Tepezcuintles Cuniculus paca (syn. Agouti paca) en cautiverio en Yucatán
}

\author{
Report of rabies in Tepezcuintles Cuniculus paca (syn. Agouti paca) in captivity in \\ Yucatan
Montes-Pérez Rubén ${ }^{1}$ ID, Cabrera-Baz Elsy², Quiñones-Espinosa Rebeca ${ }^{3}$, Sierra- Lira Eduardo 4

${ }^{1}$ Facultad de Medicina Veterinaria y Zootecnia, Universidad Autónoma de Yucatán. Mérida, Yucatán, México. ${ }^{2}$ Práctica privada. Tuxtla Gutiérrez, Chiapas, México. ${ }^{3}$ Práctica privada. Mérida, Yucatán, México. ${ }^{4}$ Práctica privada. Mérida, Yucatán México. Autor de correspondencia: Rubén Montes-Pérez. Facultad de Medicina Veterinaria y Zootecnia, Universidad Autónoma de Yucatán. Mérida, Yucatán, México. mperez@correo.uady.mx, mamatepez@gmail.com, zulerebe@hotmail.com,

eduardosierralira.esl@gmail.com.

\section{Resumen}

El objetivo del presente estudio de caso es informar la presencia de rabia en tres ejemplares de Cuniculus paca, mantenidos en cautiverio en Yucatán, México. Se registraron los signos clínicos de los ejemplares previos al deceso de cada uno, se colectó el cerebro para ser enviado a laboratorio certificado de patología animal, donde se aplicó la técnica de inmunofluorescencia para detectar la nucleoproteína del Lyssavirus. Se describió el cuadro clínico de cada uno de los ejemplares afectados. Los resultados mostraron positividad a la reacción inmunológica.

Palabras clave: Lyssavirus, rabia, zoonosis, fauna silvestre.

\begin{abstract}
The objective of this case study is to report the presence of rabies in three Cuniculus paca specimens, of kept in captivity, in Yucatan, Mexico. The specimens' clinical signs were recorded before the death of each one, the brain was collected and sent to a certified animal pathology laboratory, to detect the Lyssavirus nucleoprotein by the immunofluorescence technique. The clinical picture of each of the affected specimens was described. The results showed positivity to the immune reaction.
\end{abstract}

Keywords: Lyssavirus, rabies, zoonosis, wildlife.

\section{INTRODUCCIÓN}

La rabia es una zoonosis de amplia distribución geográfica, el agente etiológico es un virus neurotrópico del género Lyssavirus, de la familia Rhabdoviridae, del orden Mononegavirales, que provoca lesiones en el sistema nervioso central (SNC) que son irreversibles; mismas que conducen a la muerte por parálisis (Torres et al., 2019). La presencia del virus rábico se extiende en todo el planeta, excepto Antártida, especialmente es elevada la prevalencia en regiones de África y Asia, fundamentalmente en niños menores de 15 años (Frantchez y Medina, 2018). Existen huéspedes susceptibles en Yucatán que son zorrillos de los géneros Spilogale y Conepatus, murciélago hematófago de los géneros Desmodus y Diphilia, mapaches (Procyon lotor) y tejon (Nasua narica) (Ortega-Pacheco y Jlménez, 2017). 
Se reconoce que el cuadro clínico de la rabia clásica humana cursa por tres etapas: incubación, pródromo y neurológica aguda. La primera fase ocurre a partir del ingreso del virus por laceración o mordida, generalmente dura de uno a tres meses; pero puede durar unos días cuando la penetración del virus es cerca del cuello o cabeza, e incluso directamente al tejido nervioso; pero también puede permanecer varios años antes de continuar con la siguiente etapa, por esta razón puede pasar inadvertida. La segunda etapa dura generalmente de dos a 10 días, el virus ha migrado por el sistema nervioso central, y el paciente exhibe signos de fiebre, cefalea, malestar general, irritabilidad, náuseas y vómito. La tercera fase dura desde horas hasta una semana, se manifiesta como rabia encefalítica o paralítica; principalmente aparece fiebre, hipersalivación, sudoración excesiva, piloerección, anomalías pupilares, arritmias cardiacas, edema pulmonar, parálisis del diafragma y bulbar (Frantchez y Medina, 2018).

Existen dos tipos de rabia, la encefalítica o furiosa y la paralítica; la furiosa es la más frecuente, los signos son: hiperexcitabilidad por estímulos, como ruido o luz, alucinaciones, salivación excesiva, hidrofobia y aerofobia. La paralítica muestra parálisis de las extremidades posteriores e incontinencia urinaria (Frantchez y Medina, 2018).

El diagnóstico de la rabia se realiza principalmente por inmunofluorescencia (IF) en tejido cerebral, por cultivo celular, inoculación en ratón o genotipificacion por PCR (OMS, 2013); porque la observación clínica solo indica sospecha de rabia en las primeras etapas del curso de la enfermedad, cuando ésta se manifiesta es debido a que se alteran las funciones de neuronas CB-ir (GABA-ergicas), en la fase terminal del cuadro clínico de rabia, cuando el virus se ha diseminado en la mayor parte de las áreas del cerebro (Lamprea y Torres-Fernández, 2008). En C. paca se ha reportado la presencia de rabia solo en un caso previo en Guatemala (Díaz et al., 1962); estos autores también reportan presencia de rabia en las siguientes especies de fauna silvestre: tacuatzin (Philandel opossum fuscogriseus y Didelphys marsupiales), murciélagos (Molossus sinaloae, Phyllostomidae sp, y Artibeus literatus palmorum), zorro (Urocyon cinereargenteus), mapaches (Procyon lotor), coyotes (Canis latrans) y zorrillos (Conepatus mapuritus).

El objetivo de este reporte es comunicar la presencia de rabia en tres ejemplares de Cuniculus paca mantenidos en cautiverio en Yucatán, México.

\section{PRESENTACIÓN DEL CASO CLÍNICO}

Los casos clínicos aparecieron en la Unidad de Manejo para la Conservación de Vida Silvestre Xmatkuil, ubicada en la ciudad de Mérida, Yucatán, México. El primer caso clínico, fue una hembra adulta (número 03), que el 24 de marzo de 1999 presentó irritabilidad, anorexia y emaciación (disminución de condición corporal). A los seis días de iniciado el cuadro clínico manifestó intolerancia a la presencia del macho sin número de identificación, con el cual compartía corral, impidiendo su acceso a la madriguera; causándole heridas cutáneas superficiales por mordedura, las cuales fueron tratadas con antisépticos. Tres días después de haber sido agredido el macho (animal sin número) presentó ligera irritabilidad; sin embargo, continuó el consumo de alimentos, 
aunque de manera irregular; pero a lo largo de los días mostró disminución de su condición corporal. Al día 12 de observación del primer caso, la hembra presentó ataxia moderada de miembros posteriores y fotofobia; en el macho se observaron nuevas lesiones por mordedura en los costados del cuerpo y en el pene, lo cual motivó la separación de animales en corrales diferentes.

En el día 14, la hembra 03 se postró y murió, procediéndose a realizar la necropsia y extracción del cerebro. El tejido cerebral se conservó en refrigeración a $10{ }^{\circ} \mathrm{C}$ para realizar examen por inmunofluorescencia en el laboratorio Central Regional de Mérida, Yucatán (LCRM). El mismo día se detectó en el macho grave depresión y anorexia, muriendo al día siguiente (9 días postmordedura); realizándose la colecta de encéfalo para efectuar el mismo examen de laboratorio.

En la primera semana de abril, la hembra juvenil número 02 , mostró irritabilidad, anorexia y pérdida de condición corporal; iniciando el día uno de observación del nuevo evento. Al día siguiente la hembra se postró, manifestando ataxia severa de miembros posteriores. Al tercer día mostró notoria disnea y continuó la anorexia. Durante los días cuatro y cinco de iniciado el cuadro clínico se notó mayor agresividad y fotofobia.

Al día 13 se observó pelo hirsuto, hipotermia y parálisis de miembros posteriores; al día 14 amaneció severamente deprimida y murió; al cadáver se le practicaron los procedimientos de estudio antes señalados. Los encéfalos de los tres animales investigados fueron positivos a rabia por inmunofluorescencia (figuras 1 y 2 ). La tabla 1 , muestra los datos resumidos de los tres casos. La figura 3, muestra a los tepezcuintles afectados por virus rábico y uno de los encéfalos que fue enviado al laboratorio para el examen de inmunofluorescencia.

Tabla 1. Información resumida de los animales que murieron por causa de rabia

\begin{tabular}{|c|c|c|c|c|c|}
\hline $\begin{array}{lr}\text { Número } & \text { del } \\
\text { animal } & y \\
\text { sexo } & \end{array}$ & $\begin{array}{l}\text { Duración } \\
\text { proceso }\end{array}$ & $\begin{array}{l}\text { Fecha } \\
\text { muerte }\end{array}$ & $\begin{array}{l}\text { Diagnóstico } \\
\text { inmunofluorescencia } \\
\text { tejido cerebral }\end{array}$ & $\begin{array}{r}\text { por } \\
\text { en }\end{array}$ & Observaciones en el animal \\
\hline 03 Hembra & $\begin{array}{l}\text { Subagudo } \\
\text { Inició } \\
24 / 03 / 1999 \\
\text { Duración } \\
\text { días }\end{array}$ & 6/04/1999 & $\begin{array}{l}\text { Positivo a rabia. } \\
\text { Estudio con número } \\
\text { folio } 34520\end{array}$ & de & $\begin{array}{l}\text {-marcada agresividad. } \\
\text { - irritabilidad. } \\
\text {-ataxia de miembros posteriores. } \\
\text { - sialorrea. } \\
\text {-fotofobia. } \\
\text {-anorexia. } \\
\text {-emaciación. }\end{array}$ \\
\hline S/N Macho & $\begin{array}{l}\text { Subagudo, } \\
\text { mordido } \\
\text { 30/03/1999 } \\
\text { Duración } 9 \text { días }\end{array}$ & 7/04/1999 & $\begin{array}{l}\text { Positivo a rabia. } \\
\text { Estudio con número } \\
\text { folio } 34520\end{array}$ & de & $\begin{array}{l}\text {-irritabilidad. } \\
\text {-disminución de condición corporal. } \\
\text {-depresión grave. } \\
\text { - anorexia. }\end{array}$ \\
\hline $\begin{array}{l}02 \text { Hembra } \\
\text { juvenil }\end{array}$ & $\begin{array}{l}\text { Subagudo } \\
\text { Inició 6/04/1999 } \\
\text { Duración } 14 \\
\text { días }\end{array}$ & 19/04/1999 & $\begin{array}{l}\text { Positivo a rabia. } \\
\text { Estudio con número } \\
\text { folio } 34680\end{array}$ & de & $\begin{array}{l}\text {-irritabilidad. } \\
\text {-agresividad. } \\
\text {-disminución de condición corporal. } \\
\text { - hipotermia. } \\
\text {-parálisis de miembros posteriores } \\
\text { (ataxia). } \\
\text { - fotofobia. } \\
\text { - apnea. } \\
\text {-anorexia. } \\
\text { - Pelo hirsuto }\end{array}$ \\
\hline
\end{tabular}




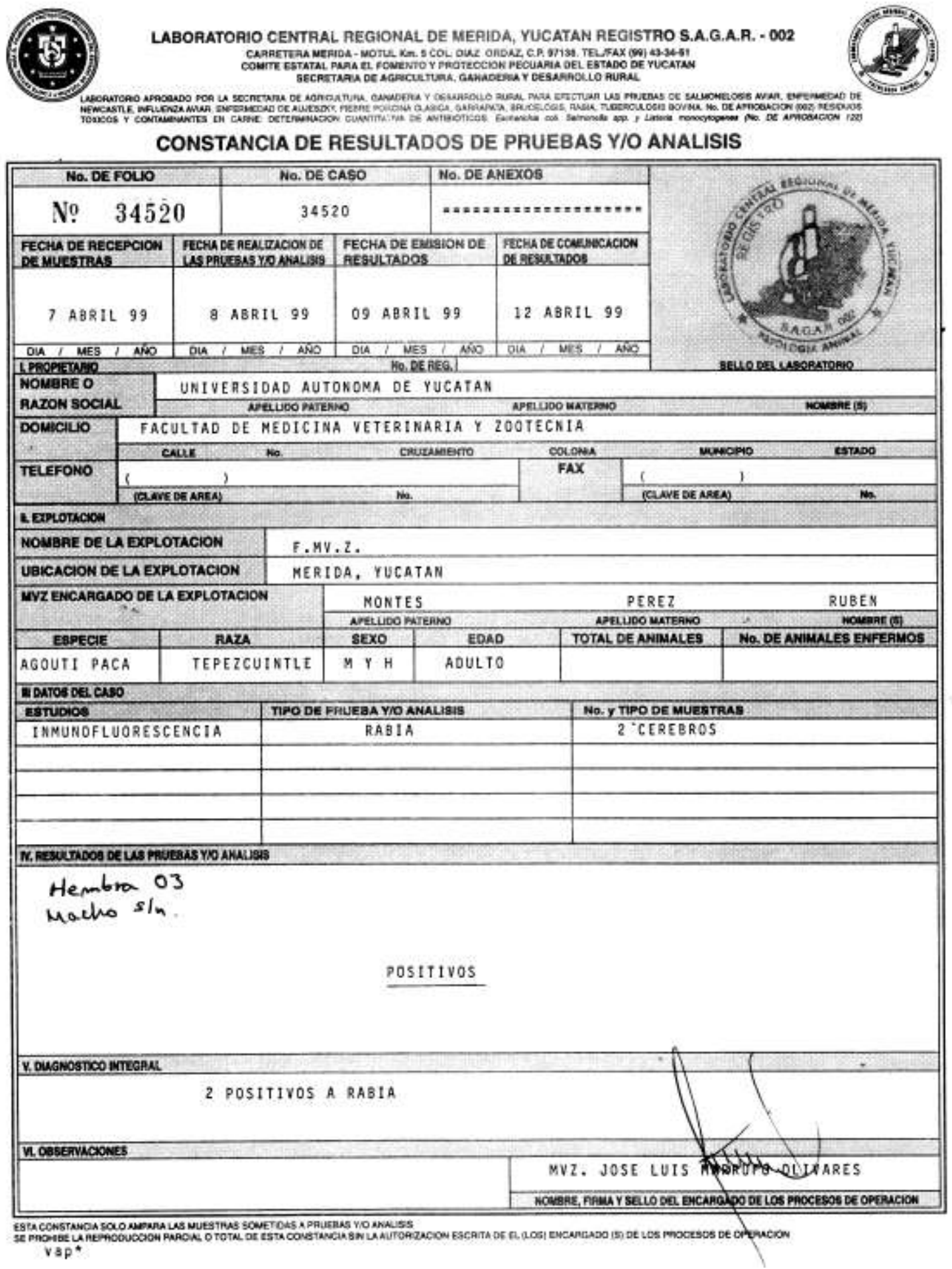

Figura 1. Constancia de positividad a rabia por la prueba de inmunofluorescencia en tejido cerebral de Cuniculus paca, hembra 03 y macho sin número 
LABORATORIO CENTAAL REGIONAL DE MEAIDA, YUCATAN REGISTRO S.A.G.A.R. - 002

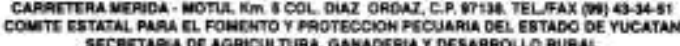

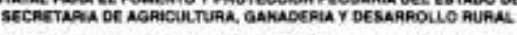

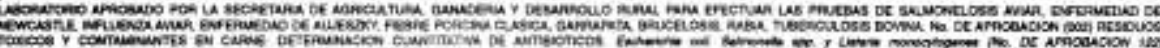

CONSTANCIA DE RESULTADOS DE PRUEBAS YIO ANALISIS

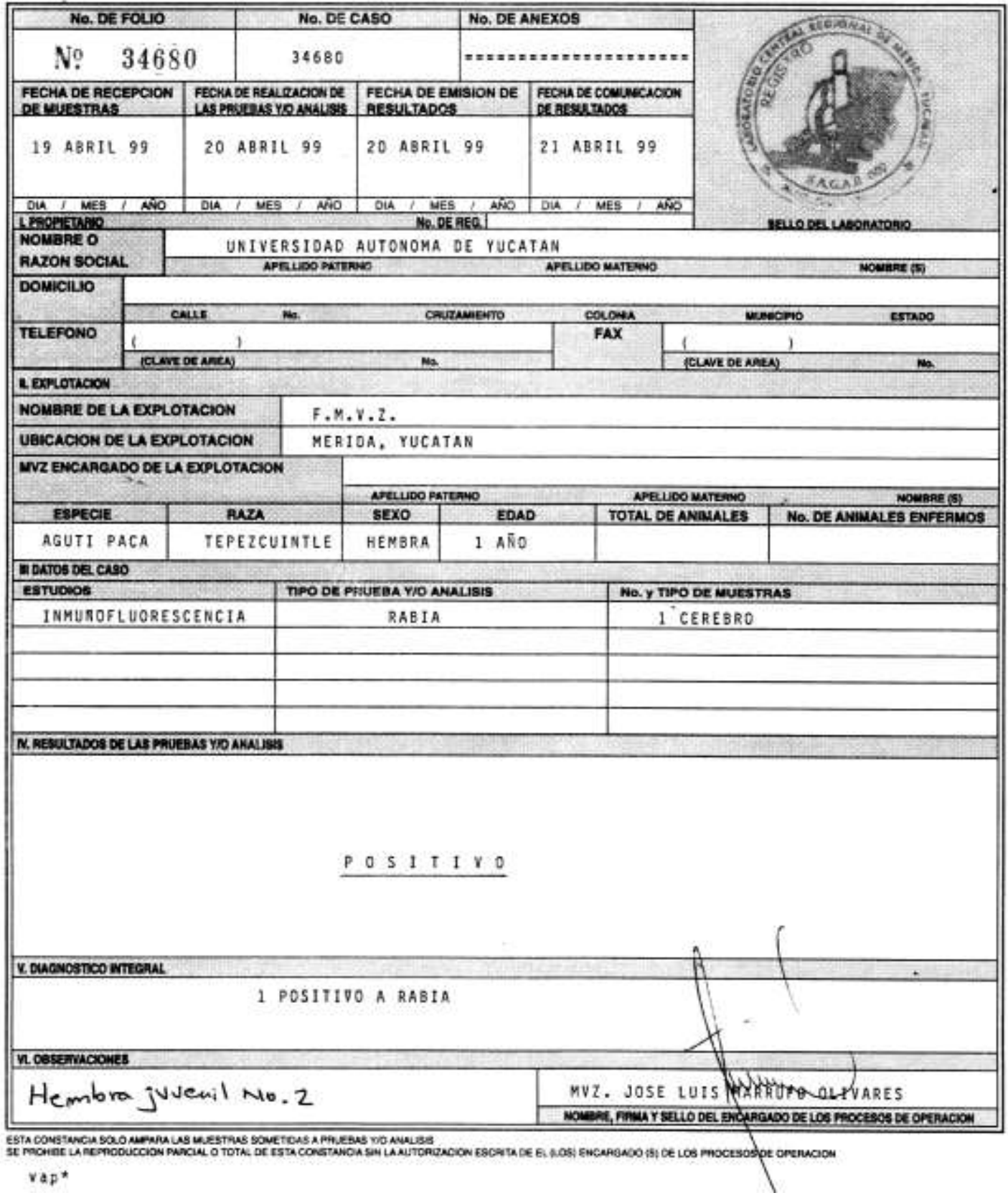

Figura 2. Constancia de positividad a rabia por la prueba de inmunofluorescencia en tejido cerebral de Cuniculus paca, hembra juvenil 2 


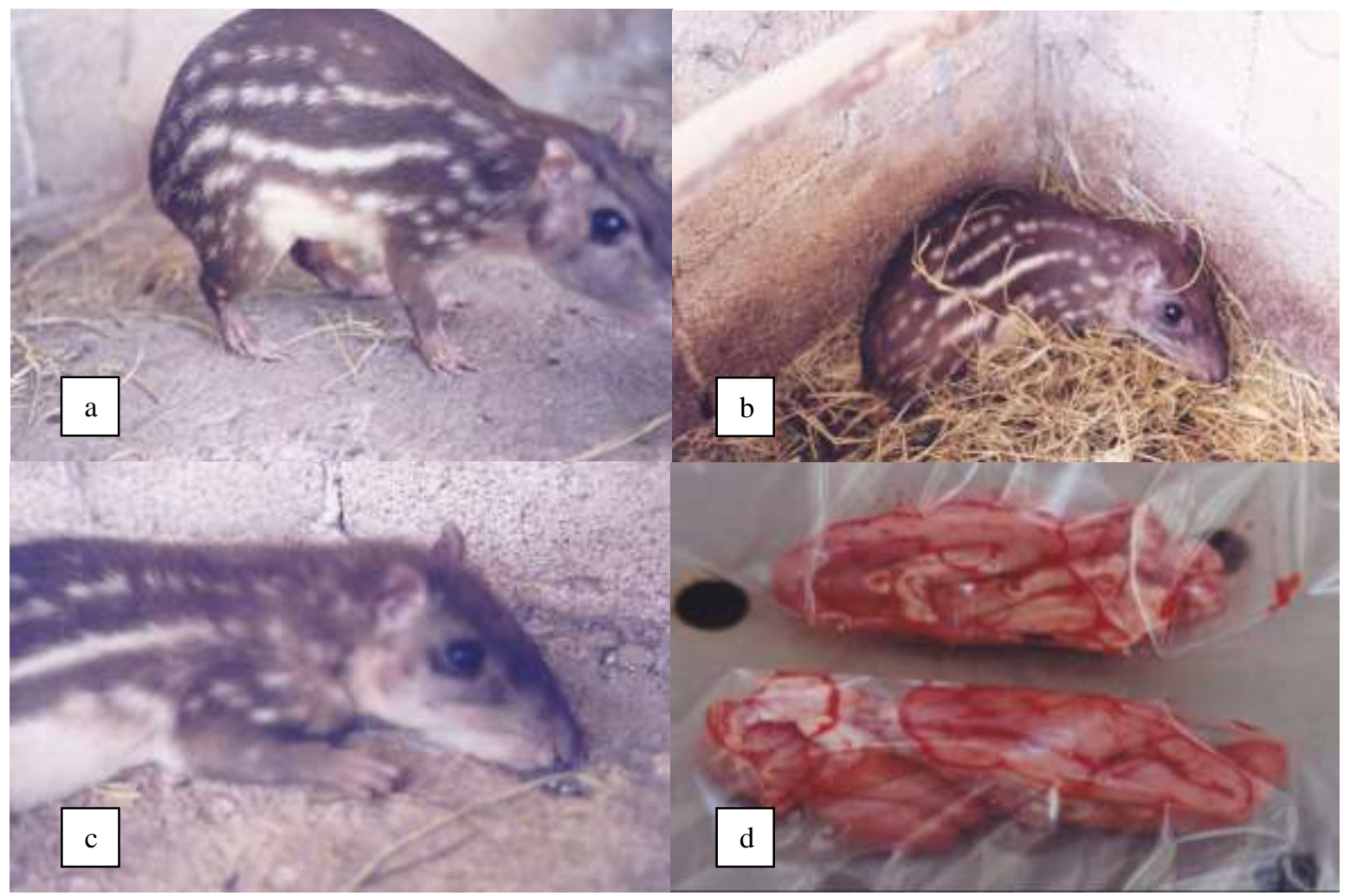

Figura 3. Tepezcuintles Cuniculus paca macho con signos de rabia y encéfalo. a) tepezcuintle Cuniculus paca macho sin número, mordido por la hembra 03, b) tepezcuintle hembra juvenil 02 postrada al día 11 de iniciado su cuadro clínico, c) hembra 02 juvenil al día 13 de iniciado el cuadro clínico y d) las dos mitades del encéfalo de la hembra juvenil 02.

\section{DISCUSIÓN}

En general los signos clínicos presentados en los tres casos, mostraron signos similares; se observó que en las hembras la fase furiosa fue más evidente que en el macho; sin embargo, a diferencia de lo descrito en la literatura médica para otras especies animales, los tepezcuintles (C. paca) que sufrieron agresiones en los corrales no intentaron morderse las heridas. El macho del segundo caso, no presentó fotofobia ni sialorrea, la duración de la fase paralítica fue de nueve días y no de horas, como lo mencionan Frantchez y Medina (2018). A pesar de que no se pudo identificar al agresor primario que introdujo al virus correspondiente al primer y tercer caso, es importante considerar que se presentan diferencias clínicas conductuales en los animales enfermos, de acuerdo a la especie del agresor que causó la infección. Cuando es un carnívoro como el perro, se vuelve predominantemente furiosa, y en cambio cuando es un quiróptero (en especial el murciélago hematófago, Desmodus rotundus), predomina la fase paralítica, como se manifiesta en bovinos (Ibáñez y Chang, 2019; Sánchez et al., 2019). Debido a que los hábitos conductuales de los tepezcuintles son nocturnos, 
suponemos que es poco probable que el virus haya sido introducido por murciélago. En los casos de los tepezcuintles, solo en un macho (caso No. 2), mordido por su pareja enferma, se pudo determinar la fuente de infección original; encontrándose que solo la fotofobia y la sialorrea, diferenciaron los cuadros clínicos entre la pareja.

Es posible suponer que tuvieron alguna relación, en la severidad de los cuadros observados entre las hembras y el macho, las heridas que constituyeron la puerta de entrada al virus rábico, puesto que en las hembras durante la inspección clínica no se pudieron hallar laceraciones o soluciones de continuidad en la piel; en cambio el macho mostró herida franca causada por dientes, la cual presentaba residuos de saliva en el pelo. Frantchez y Medina, (2018), mencionan que la ubicación corporal y la severidad de las heridas, determinan en gran parte la duración del periodo de incubación, del curso de la enfermedad y de la transición entre las fases agresiva y paralítica; esto puede explicar la razón por la que el tepezcuintle macho, mostró menor duración de su patología, en virtud de que fue mordido en el pene, que está abundantemente vascularizado e inervado por el sistema nervioso simpático y parasimpático (Vozmediano y Bonilla, 2010) y en la región media del cuerpo.

EI LCRM está certificado por el Instituto Nacional de Referencia Epidemiológica de México, para efectuar el diagnóstico de rabia, mediante la técnica de IF en tejido cerebral, por tanto el diagnóstico es altamente confiable; además que esta técnica tiene sensibilidad hasta del 99\% (Secretaría de Salud, 2012).

\section{LITERATURA CITADA}

DIAZ LH, Santamaría JG, Otal AU. 1962. Datos sobre la situación de la rabia en Guatemala. Salud Pública de México. Epoca V. 4(2): 247-251. ISSN: 1606-7916. http://saludpublica.mx/index.php/spm/article/viewFile/4177/4058

FRANTCHEZ V, Medina J. 2018. Rabia: 99.9\% mortal, 100\% prevenible. Revista Médica del Uruguay. 34(3):164-171. ISSN 1688-0390. http://www.scielo.edu.uy/pdf/rmu/v34n3/1688-0390-rmu-34-03-86.pdf

IBAÑEZ MM, Chang RE. 2019. La Rabia en la Patagonia. Desde La Patagonia Difundiendo Saberes. $\quad$ 16(28): 24-28. ISSN 2618-5385. https://repositorio.inta.gob.ar/xmlui/bitstream/handle/20.500.12123/6555/INTA_CRPatag oniaNorte_EEABariloche_ChangReissig_E_La_Rabia_En_La_Patagonia.pdf?sequence $=1$ \&isAllowed $=y$

LAMPREA N. Torres-Fernández O. 2008. Evaluación inmunohistoquímica de la expresión de calbindina en el cerebro de ratones en diferentes tiempos después de la inoculación con el virus de la rabia. Colombia Médica. 39 (3): 7-13. ISSN: 0120-8322. https://www.redalyc.org/articulo.oa?id=28309602 
OMS ORGANIZACION MUNDIAL DE LA SALUD. 2013. Reunión Consultativa de expertos de la OMS sobre la rabia: segundo informe. Serie de informes técnicos de la

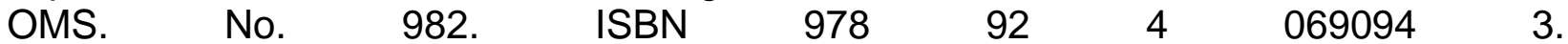
https://www.paho.org/panaftosa/index.php?option=com_docman\&view=download\&slug= consulta-expertos-oms-sobre-rabia-espanol-0\&ltemid $=518$

ORTEGA-PACHECO A, Jiménez M. 2017. La rabia canina, una zoonosis latente en Yucatán. Revista Biomédica. 28 (2): 61-63. ISSN 2007-8447. https://www.researchgate.net/publication/328397960_La_rabia_canina_una_zoonosis_I atente_en_Yucatan

SANCHEZ MP, Díaz SOA, Sanmiguel RA, Ramirez AA, Escobar L. 2019. Rabia en las Américas, varios desafíos y "Una sola salud": artículo de revisión. Revista de Investigación Veterinaria. 30(4): 1361-1381. http://www.scielo.org.pe/scielo.php?pid=S1609$91172019000400001 \&$ script=sci_abstract

SECRETARIA DE SALUD. Dirección General de Epidemiología. Grupo Técnico Interinstitucional del Comité Nacional para la Vigilancia Epidemiológica (CoNaVE). 2012 Manual de Procedimientos Estandarizados para la Vigilancia Epidemiológica de la Rabia en Humano. ISBN sin número. http://187.191.75.115/gobmx/salud/documentos/manuales/27_Manual_RabiaenHumano .pdf

TORRES MBB, Domínguez MY, Rodríguez NJA. 2019. La rabia como enfermedad reemergente. Medicentro Electrónica. 23(3): 238-248. ISSN-e 10293043. https://www.medigraphic.com/pdfs/medicentro/cmc-2019/cmc193g.pdf

VOZMEDIANO RCh, Bonilla PR. 2010. Recuerdo y actualización de las bases anatómicas del pene. Archivos Españoles de Urología. 63(8): 575-580. ISSN 00040614. http://scielo.isciii.es/scielo.php?script=sci_arttext\&pid=S000406142010000800002 